\title{
Preparation and composition of sebacic acid
}

\section{J. Redtenbacher}

To cite this article: J. Redtenbacher (1842) Preparation and composition of sebacic acid, Philosophical Magazine Series 3, 20:129, 168-169, DOI: 10.1080/14786444208650541

To link to this article: http://dx.doi.org/10.1080/14786444208650541

册 Published online: 01 Jun 2009.

Submit your article to this journal $\pi$

Џ Article views: 2

Q View related articles $\sqsubset$ 
determining their strength. From experiments on hollow pillars of cast-iron, formulæ representing the strength of such pillars are, in like manner, deduced.

The strength of pillars of wrought iron and of timber, in relation to their dimensions, is made the subject of another series of experiments. The result for wrought iron is, that the strength varies inversely as the square of the length of the pillar, and directly as the power 3.75 of its diameter, the latter being nearly identical with the result obtained for cast iron; while in timber, the strength varies nearly as the fourth power of the side of the square forming the section of the pillar. In like manner, the power of cast-iron pillars to resist long-continued pressure, and the relative strengths of long pillars of cast iron, wrought iron, steel and timber, are determined.

The inquiry which constitutes the subject of this paper is not, however, the first of the kind in which Mr. Hodgkinson has been engaged; several series of experiments and papers on the strength of iron, in various forms, have been published by him at different times; and their accuracy has established his claim to our confidence on the present occasion.

[The remainder of the Anniversary Proceedings will be given next month.]

XXVI. Intelligence and Miscellaneous Articles.

PREPaRation and Compositjon OF SEBaCIC ACID. BY

\section{J. REDTENBACHER.}

W THÉNARD prepared this acid by treating the products of the distillation of most fatty bodies with boiling water; as the solution cools, foliated crystals of the acid separate; these are purified by adding acetate of lead to the aqueous solution, and by decomposing the precipitate with hydrosulphuric acid.

Berzelius prepared this acid by boiling the product of the distillation of fatty bodies with carbonate of lime diffused through a large quantity of water, and decomposing the sebate of lime formed by nitric acid. Berzelius supposed the acid thus produced to be benzoic acid modified by some empyreumatic matter.

MM. Dumas and Peligot gave the following as the composition of hydrated sebacic acid: $\mathrm{C}^{10} \mathrm{H}^{16} \mathrm{O}^{3}+\mathrm{H}^{2} \mathrm{O}$, the water being separable by an equivalent of a metallic base; with this the analysis of $M$. Redtenbacher agrees.

After relating various experiments on the preparation of this acid, M. Redtenbacher observes, that the greater part of fatty bodies, both of animal and vegetable origin, yield sebacic acid when they are distilled, as ox-fat, hog's-lard, olive-oil, \&c. Neither stearin nor margaric acid, nor glycerin, when they are pure, yield the smallest trace of sebacic acid by distillation : as fats and oils contain only oleic acid besides the three compounds above named, it follows as a necessary conclusion, that sebacic acid is produced from it by distillation.

When oleic acid is distilled alone, the product, among other substances, contains a large portion of sebacic acid, the quantity of 
which is not increased when the oleic acid employed contains other fixed fatty acids : wax yields no sebacic acid by distillation, therefore it contains no oleic acid, nor does spermaceti. M. Thénard has indeed indicated the formation of sebacic acid during the distillation of wax, as a means of determining whether it is adulterated with fat.

As sebacic acid is but very sparingly soluble in cold water, it is easily recognised, both by its appearance and its reaction with the salts of lead, mercury, and silver; and as it is sufficient to distil less than an ounce of any fatty body, the sebacic acid from the product of which is easily separated by boiling water, it must be admitted that sebacic acid is the best reagent for detecting the presence of oleic acid in a fatty matter. This fact is especially important in the preparation of margarin and stearin, the only method which has been hitherto employed consisting in the saponification of the fatty matter, and ascertaining the fusing point of the fatty acid set free.

The best process which can be employed for the preparation of sebacic acid is that of distilling the rough oleic acid produced in the manufacture of stearin candles.-Ann. de Chim. et de Phys., Sept. 1841.

\section{EUCHROJC ACID.}

M. Wœhler finds, that when mellitate of ammonia is heated to $302^{\circ}$ Fahr. much ammonia is evolved and water evaporated, and the salt is converted into two new azotized bodies, one of which is an acid and remains combined with ammonia, in the form of an ammoniacal salt, while the other is quite insoluble in water. The disengagement of ammonia commences at $212^{\circ}$, and when the temperature is raised to above $320^{\circ} \mathrm{Fahr}$, secondary products are formed which interfere with the results.

When the decomposition is complete, the salt is changed into a pale yellow powder which is separated by water into two substances, namely, an ammoniacal salt which is dissolved, and a white substance which remains undissolved; the former is euchroate of ammonia, and the latter paramide.

If the decomposition has not been complete, the euchroate of ammonia contains excess of acid, or rather supereuchroate of ammonia; and if the heat be too great, the yellow bitter substance already mentioned is produced. The ammoniacal salt with excess of acid is deposited in imperfectly crystalline scales, which are but sparingly soluble in cold water, and have a strongly acid reaction.

To obtain the acid from the ammoniacal salt, it is to be dissolved in the smallest possible quantity of boiling water, and nitric or hydrochloric acid is to be added to the hot solution. As soon as the temperature is lowered a few degrees, the euchroic acid begins to separate in the form of a white crystalline powder, and after cooling but little of it remains in solution. It is to be purified by repeated solution in hot water and crystallization; by long and well managed cooling, small, but very distinct crystals are obtained.

This acid crystallizes in very flat four-sided prisms, which are 